\title{
Improvement of germination rate and in vitro multiplication of Lavandula angustifolia
}

\author{
Slimani Chaimae ${ }^{1,2 *}$, Sqalli Hakima ${ }^{3}$, Rais Chaimae ${ }^{4}$, Squalli Wafae $^{1}$, Abderrahim Lazraq $^{1}$, El Ghadraoui Lahsen ${ }^{1}$, \\ Belmalha Saadia ${ }^{2}$, Echchgadda Ghizlane ${ }^{2}$ \\ ${ }^{1}$ Laboratory of Functional Ecology and Environment, Faculty of Sciences and Technology, Sidi Mohamed Ben Abdellah University, Fez, Morocco \\ ${ }^{2}$ Laboratory of Plant Protection and Environment, National School of Agriculture of Meknes, Meknes Morocco \\ ${ }^{3}$ Laboratory of Microbial Biotechnology, Faculty of Sciences and Technology, Sidi Mohamed Ben Abdellah University, Fez, Morocco \\ ${ }^{4}$ Laboratory of botany, National Agency for Medicinal and Aromatic Plants, Taounate, Morocco
}

\section{ARTICLE INFO}

Article history:

Received on: May 31, 2019

Accepted on: September 26, 2019

Available online: March 26, 2020

\section{Key words:}

Lavandula angustifolia, physical treatment, chemical treatment, $A G 3, B A P, N A A$

\begin{abstract}
Lavender is well-known for its essential oils, which are in high demand and have a very important economic interest, particularly for the pharmaceutical and cosmetic industries. This work had been done to study seed germination and in vitro culture of Lavandula angustifolia. The seeds of L. angustifolia had undergone a vernalization followed by two treatments (physical and chemical), in order to increase the percentage of germination. Seeds were introduced into tubes containing the culture medium Murashige et Skoog (MS). Untreated seeds were germinated in the same medium supplemented with gibberellic acid at different concentrations. The kinetics, the speed, and the final germination rate were retained in order to evaluate the response of seeds. The micropropagation of L. angustifolia was performed on MS medium supplemented with different concentrations of 6-Benzylaminopurine (Treatment I) and 6-Benzylaminopurine in combination with Naphthalene Acetic Acid (Treatment II). Multiplication rate, shoots number, nodes number, leaves number, and stem length were determined. Lavandula angustifolia seeds revealed very low germination percentages for all the treatments used. However, those treated with sand (physical treatment) showed the highest percentage of germination $(22 \%$ ) followed by sulfuric acid treatment with a percentage of $14 \%$. Results showed that the 11.11 $\mu \mathrm{M}$ concentration of 6-Benzylaminopurine favored the maximum reactivity of the explants. The combination between 6-Benzylaminopurine and Naphthalene Acetic Acid showed that MS supplemented with $8.88 \mu \mathrm{M}$ 6-Benzylaminopurine and $2.68 \mu \mathrm{M}$ Naphthalene Acetic Acid was the most effective in the development of vitroplants.
\end{abstract}

\section{INTRODUCTION}

The genus Lavandula, belongs to the Lamiaceae family, comprises about 20 species distributed in the Mediterranean zone [1,2]. Lavandula angustifolia has been used since ancient times in perfumery and medicine to treat many ailments. From the XVIII ${ }^{\text {éme }}$ century, this spice sees growth, in France, with the development of the perfume industry and, therefore, the use of her essential oil.

\footnotetext{
*Corresponding Author

Slimani Chaimae, Laboratory of Functional Ecology and Environment, Faculty of Sciences and Technology, Sidi Mohamed Ben Abdellah University,Fez, Morocco.E-mail: Chaimae.slimani94@gmail.com
}

Today, the cultivation of $L$. angustifolia is widespread. These plants are used for therapeutic purposes, aromatic, or containing substances that can provide drugs by synthesis. The essential oils of Lavandula are highly sought by pharmaceutical, cosmetic, and perfume industries [3]. They also have many other uses, including utilization as ornamental and melliferous plants [4].

As other species, Lavandula spp. can spread sexually or asexually. Seeds multiplication is generally slow and the plants show a large variation of characteristics such as growth rate and composition of essential oil [5]. Therefore, vegetative propagation techniques are most effective at producing a large number of plants with an interest genotype.

Micropropagation can provide large-scale production under controlled conditions in a short time [6]. Although this technique 
is more expensive, a more consistent yield and quality of oil can be achieved, resulting in economic savings.

Indeed, the objective of the present work was to develop a method of regeneration by multiplication of L. angustifolia from the Azrou region and also to observe their response to different components of culture media.

\section{MATERIALS AND METHODS}

\subsection{Seed Germination Test of $L$. angustifolia and Effect of Growth Hormones}

Lavandula angustifolia seeds had a cold pre-treatment in the freezer $\left(-13^{\circ} \mathrm{C}\right)$ for 5 days. Then, they were divided into three batches: A batch treated with sulfuric acid (chemical treatment), another one scarred by sand (physical treatment), and a third batch of untreated seeds updated in the culture medium (MS), addition with gibberellic acid $\left(\mathrm{AG}_{3}\right)$ at different concentrations, namely, $2.88,5.7,8.66,11.55$, and $14.44 \mu \mathrm{M}$. Seeds were superficially disinfected with $70 \%$ alcohol for 2 minutes and decanted in $2 \%$ sodium hypochlorite solution for 20 minutes. Finally, three rinses with sterile distilled water 15 minutes each.

Culture medium's $\mathrm{pH}$ was adjusted to 5.8 before autoclaving at $120^{\circ} \mathrm{C}$ for 20 minutes and under 1 bar pressure. After transplanting, the tubes were placed in a culture room under a luminous intensity of 1,500 lux. The temperature was maintained at $20^{\circ} \mathrm{C}$, with a photoperiod of $16 / 8$ hour in darkness.

\subsubsection{Parameters studied}

Parameters to evaluate the behavior of seeds during germination were as follows:

Kinetics of the germination corresponds to the curve of the cumulative daily germination rate, calculated from the number of newly germinated seeds at each observation [7].

Germination rate characterizes the variation of germination rates from the appearance of the first radical's tips to the stability of germination. Kotowski's [8] formulas were used for calculating the Velocity Coefficient (Cv) or the Mean Germination Time (Tm).

$$
\begin{gathered}
\mathrm{Cv}=\frac{\mathrm{N} 1+\mathrm{N} 2+\mathrm{N} 3+\ldots .+\mathrm{Nn}}{\mathrm{N} 1 \mathrm{~T} 1+\mathrm{N} 2 \mathrm{~T} 2+\mathrm{N} 3 \mathrm{~T} 3+\ldots . .+\mathrm{NnTn}} \times 100 \\
\mathrm{Tm}=\frac{\mathrm{N} 1 \mathrm{~T} 1+\mathrm{N} 2 \mathrm{~T} 2+\mathrm{N} 3 \mathrm{~T} 3+\ldots .+\mathrm{NnTn}}{\mathrm{N} 1+\mathrm{N} 2+\mathrm{N} 3+\ldots .+\mathrm{Nn}}
\end{gathered}
$$

With:

- N1: Number of sprouts sprouted at time T1;

- N2: Number of seeds germinated at time T2;

- N3: Number of seeds germinated at time T3;

- Nn: Number of seeds germinated at time Tn.

Final germination rate depends on the conditions of germination and seeds treatments [9]. The final germination rate was calculated from $\mathrm{Ni}$ (percentage of germinating seeds) and $\mathrm{Nt}$ (total number of seeds used).

$$
\operatorname{Tg}=\frac{N i}{N t} \times 100
$$

\subsection{Micropropagation Test of $L$. angustifolia}

Plant material consists of L. angustifolia's nodal sections measuring $1 \mathrm{~cm}$, collected in the Azrou region. The samples have already been identified in the Scientific Institute in Rabat, Morocco with a bar code 78993. Climatic data of the area of harvest are summarized in Table 1. The explants were disinfected under a laminar flow hood, following this protocol:

Wash with water for 1 hour, soak in $70 \%$ alcohol for 2 minutes, then immerse in 10\% sodium hypochlorite solution for 20 minutes and rinse three times with sterile distilled water 15 minutes each.

The culture medium tested was MS medium supplemented with growth hormones (Table 2): 6-banzylaminopurine (BAP) and naphthalene acetic acid (NAA).

The explants were transplanted into $15 / 150 \mathrm{~mm}$ glass tubes containing $25 \mathrm{ml}$ of culture medium, placed in a culture chamber at $25^{\circ} \mathrm{C}$ and with a photoperiod of $16 / 8$ hour of darkness.

\subsubsection{Monitoring and observed parameters}

Cultures were monitored once a week to remove contaminated explants and observe their growth. Thus, the following parameters were measured:

- Multiplication rate $=$ Number of newly formed vitroplants/ Number of starting explants;

- Number of shoots;

- Number of nodes;

- Number of leaves for each newly formed explant;

- Length of the stem.

Table 1: Principal climatic data of the studied station.

\begin{tabular}{lc} 
Climatic data & Station \\
Latitude & AZROU \\
Longitude & $33^{\circ} 26^{\prime} 03^{\prime \prime} \mathrm{N}$ \\
Altitude & $5^{\circ} 13^{\prime} 16^{\prime \prime} \mathrm{W}$ \\
Bioclimatic stage & $1,277 \mathrm{~m}$ \\
\hline $\boldsymbol{N}=$ North; $\boldsymbol{W}=$ Western. & humid \\
\hline
\end{tabular}

Table 2: Different concentrations of hormones tested.

\begin{tabular}{ccccc}
\multicolumn{2}{c}{ Treatment I } & \multicolumn{3}{c}{ Treatment II } \\
Basic medium & BAP $(\boldsymbol{\mu M})$ & Basic medium & NAA $(\boldsymbol{\mu M})$ & BAP $(\boldsymbol{\mu M})$ \\
$\mathrm{M}_{1.1}$ & 4.44 & $\mathrm{M}_{2.1}$ & 2.68 & 4.44 \\
$\mathrm{M}_{1.2}$ & 6.66 & $\mathrm{M}_{2.2}$ & 2.68 & 6.66 \\
$\mathrm{M}_{1.3}$ & 8.88 & $\mathrm{M}_{2.3}$ & 2.68 & 8.88 \\
$\mathrm{M}_{1.4}$ & 11.11 & $\mathrm{M}_{2.4}$ & 2.68 & 11.11 \\
$\mathrm{M}_{1.5}$ & 13.32 & $\mathrm{M}_{2.5}$ & 2.68 & 13.32 \\
\hline
\end{tabular}

Treatment I: MS supplemented with BAP.

Treatment II: MS supplemented with NAA \& BAP (Leelavathi et al., 2013). $\mathrm{BAP}=6$-banzylaminopurine, NAA = naphthalene acetic acid 


\subsection{Statistical Analysis}

The data were analyzed statistically [averaging, analysis of the variance (ANOVA), and standard deviation] to find the variability between the different treatments. The data were processed using the "SYSTAT 12" software. A test of averages comparison (Tukey) was made each time there was a significant effect of factor studied by the ANOVA. Results presented as a percentage were transformed to meet the conditions of distributions normality and variances equality. This angular transformation was carried out according to the following formula: $Y=2 \operatorname{ArcSin} \sqrt{ } x / 100$ [10].

\section{RESULTS}

\subsection{Germination Test of $L$. angustifolia Seeds}

\subsubsection{Kinetics of germination according to treatments of L. angustifolia seeds}

The results showed that germination varies distinctly depending on the treatments used (Fig. 1). The seeds control showed no signs of germination. After 6 weeks, germination reaches $22 \%, 14 \%$, and $4.16 \%$ for sand, sulfuric acid, and $\mathrm{AG}_{3}$ treatments, respectively. The ANOVA revealed a highly significant effect for the treatment factor (ANOVA: $\mathrm{F}=737.9$, dd $1=3, p \leq 0.001$ ).

\subsubsection{Germination rate of L. angustifolia}

The highest velocity coefficient was that of seeds treated with sand $(7.69 \%)$, followed by seeds treated with pure sulfuric acid $(3.32 \%)$ (Table 3). The shortest average germination time was recorded for sand treatment (13 days) and the longest was noted in $\mathrm{AG}_{3}$ treatment (34.5 days).

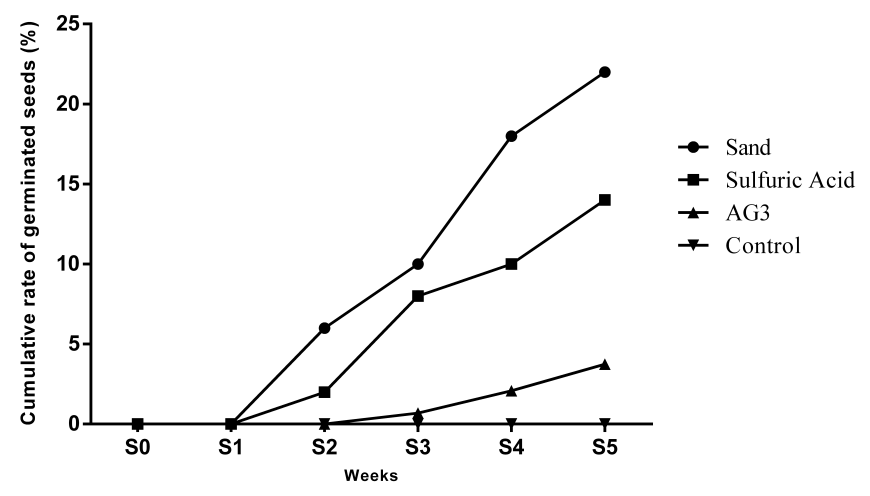

Figure 1: Kinetics of seed germination (\%) of L. angustifolia.

Table 3: Velocity coefficient and mean germination time of $L$. angustifolia seeds.

\begin{tabular}{ccc} 
& Velocity coefficient & Mean germination time \\
Sand & $7.69 \%$ & 13 days \\
Sulfuric acid & $3.32 \%$ & 30.12 days \\
Gibberellic acid & $2.28 \%$ & 34.5 days \\
\hline
\end{tabular}

\subsubsection{Final germination rate of L. angustifolia}

The highest germination rate was recorded in sand treatment (22\%), followed by $\mathrm{AG}_{3}$ treatment (14\%) (Fig. 2). The ANOVA showed highly significant differences between the treatments studied (ANOVA: $\mathrm{F}=1013.7, \mathrm{ddl}=3, p \leq 0.001$ ).

\subsection{4. $\mathrm{AG}_{3}$ effect on the germination of L. angustifolia}

It can be seen that $11.55 \mu \mathrm{M}$ showed the highest germination rate, followed by $8.66 \mu \mathrm{M}$. On the other hand, a concentration of 14.44 $\mu \mathrm{M}$ negatively affected germination and this can be explained by phyto-toxicity (Fig. 3). The statistical analysis of results showed highly significant differences between the studied concentrations (ANOVA: $\mathrm{F}=527.7, \mathrm{ddl}=3, p \leq 0.001$ )

\subsection{Micropropagation Test of $L$. angustifolia}

\subsubsection{Propagation rate of $L$. angustifolia}

Days required to establish culture varies from 27 to 30 days (Table 4). The BAP induces callus formation for the $4.44 \mu \mathrm{M}$ concentration corresponding to the $\mathrm{M}_{1.1}$. The callus has a light brown color and a compact consistency.

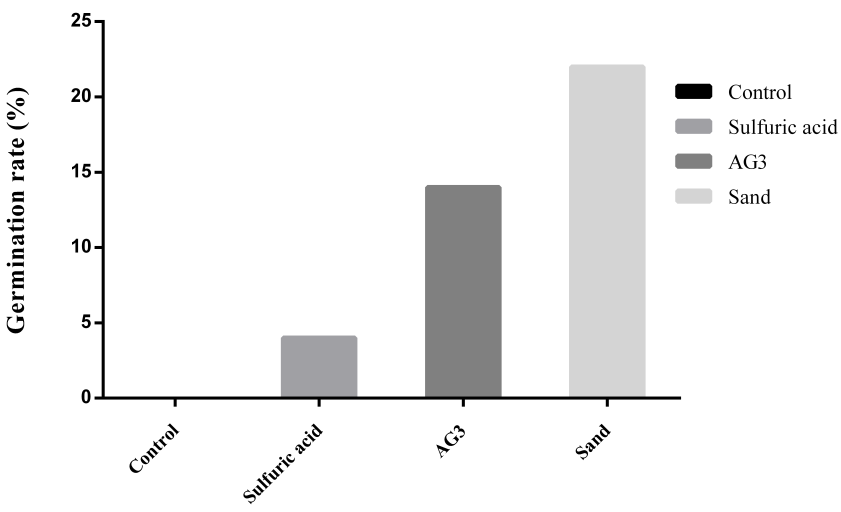

Figure 2: Final germination rate of L. angustifolia.

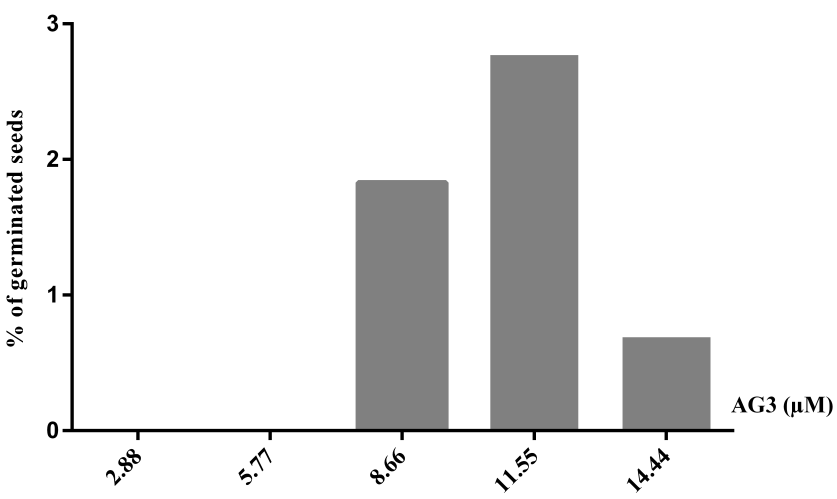

Figure 3: Effect of AG3 on the germination of L. angustifolia. 
For treatment II, the number of days required for vitroplant establishment varies from 32 to 38 days (Table 4). After 32 days of culture, the tested media induced the formation of vitroplants with no callogens, except for the $\mathrm{M}_{2.1}$ which expressed an important callogenic effect.

\subsubsection{Effect on shoots number per explant}

This study showed a variability of explant responses according to culture media. The number of shoots formed varies from 1 to 6 per explant (Fig. 4). Thus, the results showed that $\mathrm{M}_{1.4}$ was the most effective in shoots development, followed by $\mathrm{M}_{2.3}$. The ANOVA revealed a significant effect $(p \leq 0.001)$ for both, treatments and medium factors.

\subsubsection{Effect on nodes number per explants}

Medium supplemented with BAP only did not show the nodes formation, contrary to the MS supplemented with NAA (Fig. 5). Thus, $M_{2.3}$ recorded the maximum number of nodes. The analysis of the variance clearly showed highly significant effects $(p \leq 0.001)$ for both, treatments and medium factors.

\subsubsection{Effect on leaves number per explants}

The results showed that MS supplemented with BAP recorded the best responses concerning the leaves number (Fig. 6). Thus, $\mathrm{M}_{1.4}$ and $\mathrm{M}_{1.5}$ were revealed to be the most suitable medium for leaves neoformation. On the other hand, the presence of NAA, for the same concentrations, greatly reduced the leaves number. Statistical analysis showed highly significant effects $(p \leq 0.001)$ for both, treatments and medium factors.

Table 4: Effect of the media on the establishment of vitroplants.

\begin{tabular}{cccccc} 
Treatment I & Time* & $\begin{array}{c}\text { Propagation } \\
\text { rate (\%) }\end{array}$ & Treatment II & Time* $^{*}$ & $\begin{array}{c}\text { Propagation } \\
\text { rate (\%) }\end{array}$ \\
$\mathrm{M}_{1.1}$ & - & 0 & $\mathrm{M}_{2.1}$ & - & 0 \\
$\mathrm{M}_{1.2}$ & 29 days & 66.7 & $\mathrm{M}_{2.2}$ & 38 days & 33.3 \\
$\mathrm{M}_{1.3}$ & 30 days & 33.3 & $\mathrm{M}_{2.3}$ & 32 days & 33.3 \\
$\mathrm{M}_{1.4}$ & 27 days & 66.7 & $\mathrm{M}_{2.4}$ & 32 days & 66.7 \\
$\mathrm{M}_{1.5}$ & 30 days & 33.3 & $\mathrm{M}_{2.5}$ & 33 days & 33.3 \\
\hline
\end{tabular}

*Time required for the establishment of vitroplants.

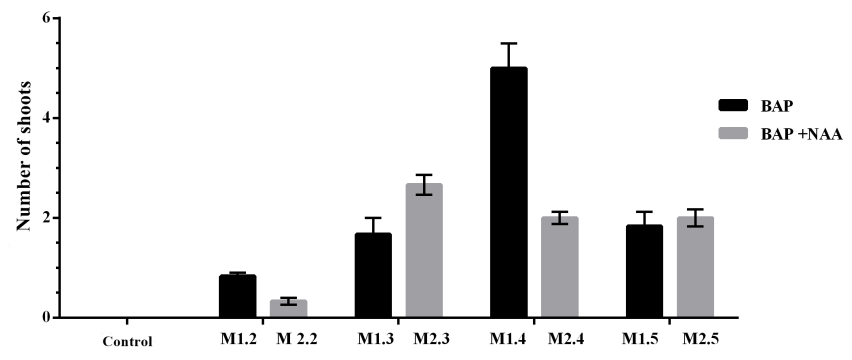

Figure 4: Effect of treatments on the number of shoots for each medium.

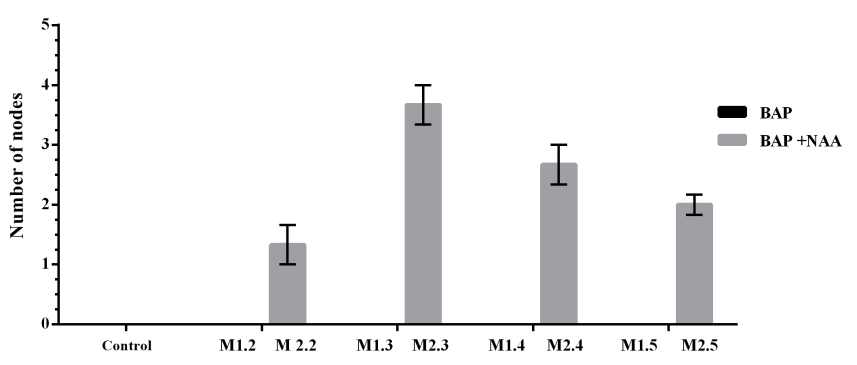

Figure 5: Effect of treatments on the number of nodes for each medium.

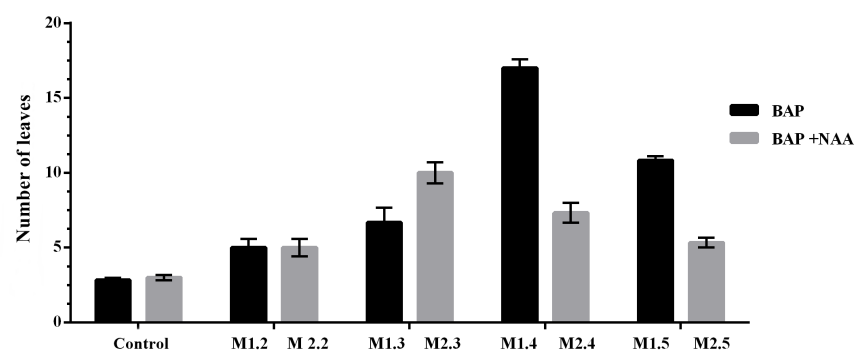

Figure 6: Effect of treatments on the number of leaves for each medium.

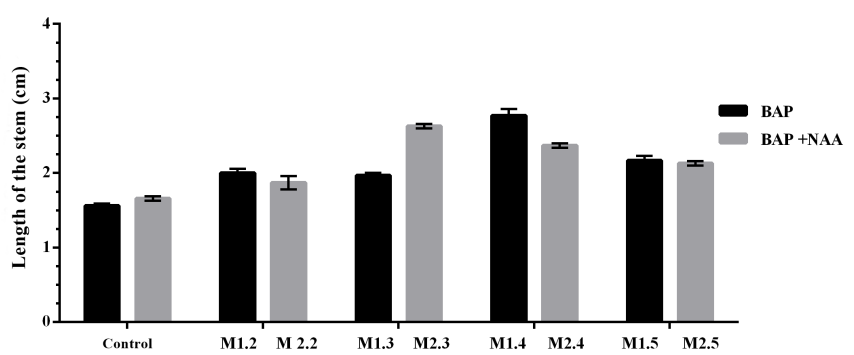

Figure 7: Effect of treatments on the length of the stem for each medium.

\subsubsection{Effect on stem length per explants}

The largest stem length was observed in $\mathrm{M}_{1.4}$ followed by $\mathrm{M}_{2.3}$ (Fig. 7). The analysis of the variance relative to $L$. angustifolia stem length showed a non-significant effect $(p>0.05)$ for the treatment factor. On the other side, statistically significant differences were recorded between the studied medium (ANOVA: $F=883.04$,ddl $=4, p \leq 0.001$ ).

\section{DISCUSSION}

Results of L. angustifolia seed germination enabled us to deduce that applied treatments were effective and necessary in comparison with the control. The kinetics, the speed, and the final germination rate allowed us to assume that sand treatment was the best to increase the germination capacity $(22 \%)$, followed by sulfuric acid treatment with a percentage of $14 \%$. 
On the other side, the results found by Mala et al. [11] indicate that the greatest percentage of $L$. angustifolia seeds germination was that of sulfuric acid treatment with $12.5 \%$, followed by sand scarification $6.25 \%$ in light, while they had the same germination percentage in dark $6.25 \%$.

The gibberellic acid induces an increase in seed germination of studied species. The most significant effect was obtained at 11.55 $\mu \mathrm{M}$ and $8.66 \mu \mathrm{M}$ concentrations.

Gibberellin was an important growth-stimulating hormone of L. angustifolia. Gibberellin treatments caused growth increases, resulted in rapid fruiting and plant improvement. The action mechanisms of this hormone were now quite well-known [12].

In the lavender seed germination study, it was shown that gibberellic treatments, with or without freezing, significantly accelerate the percentage of germination [13].

The low germination percentage recorded at a level concentration of gibberellic acid $(14.44 \mu \mathrm{M})$ seems to be related to the chemical toxicity of gibberellin, as proposed by Abdel Hady et al. [14]. According to these authors, gibberellin was a hormone whose high concentrations cause acute toxicities on animal and plant cells, long exposed to its action. Gibberellic acid can be recommended in L. angustifolia germination improvement programs, provided that the recommended concentration ranges were respected.

Regarding the micropropagation of $L$. angustifolia nodal sections, it found that the $11.11 \mu \mathrm{M}$ concentration of BAP favored the maximum explant reactivity and the combination between BAP and NAA $(8.88 \mu \mathrm{M}$ BAP $+2.68 \mu \mathrm{M}$ NAA $)$ was the more effective for the development of vitroplants.

According to Leelavathi and Narendra [5], the [MS $+8.88 \mu \mathrm{M}$ $\mathrm{BAP}+2.68 \mu \mathrm{M}$ NAA] promoted the maximum reactivity of the explant, which was in agreement with results obtained in this experiment.

Previous studies have shown that MS $+1 \mathrm{mg} / \mathrm{l} \mathrm{BAP}+0.05$ $\mathrm{mg} / \mathrm{l}$ NAA gives the best results for the number and length of L. angustifolia shoots [15]. In addition, Mitrofanova et al. [16] pointed out that several shoots are grown on MS $+0.3 \mathrm{mg} / 1$ Kinetin, $0.025 \mathrm{mg} / 1 \mathrm{NAA}$, and $0.25 \mathrm{mg} / \mathrm{l} \mathrm{GA}_{3}$.

However, the use of NAA at $0.5 \mathrm{mg} / \mathrm{ml}(2.68 \mu \mathrm{M})$ did not induce rhizogenesis. Tahmineh et al. [17] demonstrated that MS medium supplemented with $5 \mathrm{mg} / \mathrm{ml} \mathrm{NAA}$ and $5 \mathrm{mg} / \mathrm{ml}$ BAP was the best for the tissue culture of lavender. This medium gave shoots and roots after callus induction. On his side, Andrade [18] showed that the highest multiplication and rooting rate were observed with MS + BAP $(2 \mu \mathrm{M})$. Those parameters increase with the concentrations of NAA. The in vitro propagation of $L$. stoechas on the MS supplemented with a concentration ranging from $0.05 \mu \mathrm{M}$ to $5.4 \mu \mathrm{M}$ NAA allowed the rooting of seedlings for all media used [19].

\section{CONCLUSION}

Lavender is an aromatic and medicinal plant well known for many pharmacological activities. The regeneration of $L$. angustifolia is confronted with the problems of seed dormancy and the difficulty of propagation by conventional cuttings. During this work, it was contributed to the in vitro cultivation of $L$. angustifolia in order to develop a propagation method of this species. The in vitro germination of L. angustifolia seeds showed that the physical treatment (sable) allowed to have the highest percentage of germination.

The micropropagation of L. angustifolia explants on MS medium supplemented with different concentrations of BAP only and BAP in combination with NAA showed that the medium supplemented with NAA is the most effective in the development of vitroplants.

\section{REFERENCES}

1. Goday SR, Rivas-Martinez S. Atorrales y tomillares de 1a Peninsula Ibérica comprendidos en la clase Ononido-Rosmarinetea. An Inst Bot AJ Cavanilles 1947;25:5-201.

2. Rivas-Martinez S. Brezales y jarales de Europa occidental (Revisión Fitosociológica de las clases Calluno-ulicetea y Cisto-Lavanduletea). Lazaroa 1979;1:5-127.

3. Gonçalves S, Romano A. In vitro culture of lavenders (Lavandula spp.) and the production of secondary metabolites. Biotechnol Adv 2003;31:166-74; doi:10.1016/j.biotechadv.2012.09.006

4. Upson T, Andrews S. The genus Lavandula: a botanical magazine monograph. Royal Botanic Gardens, Kew, UK, pp 123-65, 2004

5. Leelavathi D, Nareudra K. Protocol for rapid clonal multiplication using in vitro apical Bud of lavandula angustifolia. J Pharm Biol Sci 2013;7:96-8. doi:10.9790/3008-0739698

6. Minh TV. Plant biotechnology. Nong Lam University Press, Ho Chi Minh City, Vietnam, p 751, 2015.

7. Hajlaoui H, Denden M, Bouslama M. Étude de la variabilité intraspécifique de tolérance au stress salin du pois chiche (Cicer arietinum L.) au stade germination. Tropicultura 2007;25:168-73.

8. Kotowski F. Temperature relations to germination of vegetable seed. Am J Soc Hortic Sci 1926;23:176-84.

9. Belkhodja M, Bidai Y. Réponse des graines d'Atriplex halimus L. sous stress salin. Rev Sécheresse 2004;15:331-5.

10. Gulumser A, Bozoglu H, Peksen E. Experimental research method. Samsun, Turkey. p 264, 2006.

11. Mala F, Parvaiza A, Shrivastava PN. In vitro seed germination studies of Lavandula angustifolia Chaix. J Pharm Biomed 2011;4:223-6. doi:10.13005/bpj/285

12. Heller R, Esnault R, Lance C. Physiologie végétale. $6^{\text {eme }}$ Ed de l'Abrégé. Éditions Dunod, Paris, France, p 294, 2006;

13. Miclea I, Chifor $\mathrm{R}$. Germination, in vitro Propagation and Acclimatization in Lavandula angustifolia. Bull UASVM Anim Sci Biotechnol 2018;75:106-9; doi:10.15835/buasvmcn-asb:2018.0017

14. Abdel-Hady MSA, Okasha MS, Soliman OM, Talaat M. Effect of gamma radiation and gibberellic acid on germination and alkaloid production in Atropa belladonna L. Aust J Basic Appl Sci 2008;2: 401-5.

15. Santos A, Gaivão I, Leal F. Micropropagation of Calendula officinalis and Lavandula angustifolia for genotoxicity and antigenotoxicity studies. Acta Hortic 2015;1083:67-73; doi:10.17660/ ActaHortic.2015.1083.6

16. Mitrofanova IV, Chirkov SN, Lesnikova-Sedoshenko NP, Chelombit SV, Zakubanskiy AV, Rabotyagov VD, et al. Micropropagation of Lavandula angustifolia Mill. 'Record' and 'Belyanka'. Acta Hortic 2017;1187:37-42; doi:10.17660/ActaHortic.2017.1187.4

17. Tahmineh SS, Raheleh AG, Setareh F. Effect of Phytohormones on Lavender (Lavandula angustiflia Mill.) Organogenesis. J Pharm Pharmacol 2015;3:338-4; doi:10.17265/2328-2150/2015.07.004 
18. Andrade LB, Echeverrigaray S, Fracaro F, Pauletti GF, Rota L. The effect of growth regulators on shoot propagation and rooting of common Lavender (Lavandula vera Dc). Plant Cell Tissue Organ Cult 1999;56:79-83; doi:10.1023/A:1006299410052

19. Nobre J. In vitro cloning and micropropagation of Lavandula stoechas from field-grown plants. Plant Cell Tissue Organ Cult 1996;46:151-5.
How to cite this article:

Chaimae S, Hakima S, Chaimae R, Wafae S, Lazraq A, Lahsen $\mathrm{E}$, et al. Improvement of germination rate and in vitro multiplication of Lavandula angustifolia. J Appl Biol Biotech 2020;8(02):52-57. DOI: 10.7324/JABB.2020.80209 